Volume 9, No.3, May - June 2020

International Journal of Advanced Trends in Computer Science and Engineering

Available Online at http://www.warse.org/IJATCSE/static/pdf/file/ijatcse121932020.pdf

https://doi.org/10.30534/ijatcse/2020/121932020

\title{
A Proposed Conception of the domain Model for Adaptive Hypermedia
}

\author{
Mehdi Tmimi $^{1}$, Kaoutar Bouskine ${ }^{2}$,Abdelkrim Khartoch ${ }^{3}$, Mohamed Benslimane ${ }^{4}$, Kamar Ouazzani $^{5}$ \\ ${ }^{1}$ Innovative Technologies Laboratory, EST, USMBA, Morocco, mehditmimi@live.fr \\ ${ }^{2}$ Innovative Technologies Laboratory, EST, USMBA, Morocco, kaoutar.bouskine@gmail.com \\ ${ }^{3}$ Innovative Technologies Laboratory, EST, USMBA, Morocco, khartoch@ gmail.com \\ ${ }^{4}$ Transmission Innovative Technologies Laboratory, EST, USMBA, Morocco, benslimane_mohamed@live.fr \\ ${ }^{5}$ Innovative Technologies Laboratory, EST, USMBA, Morocco, kamar_ouazzani@yahoo.fr
}

\begin{abstract}
In the context of adaptive learning systems, we are working on designing and developing the domain model, which is one of the three fundamental models that constitute the main architecture of adaptive hypermedia systems.
\end{abstract}

The domain model describes how the elements (knowledge and concepts) of the course are structured. Although there is a lot of domain model proposed by several reference models like (MUNICH and AHAM), and by E-learning technical standards like (SCORM and CMI5). These proposed models do not respect the context and go beyond the definition of the domain model in the sense that they introduce elements managed by other models that lead to a non-optimized structure for adaptation processes.

So, in this paper we will present our proposal of the domain model that respect and remains in the context of the definition of the model and also based on a completely new structure optimized for adaptation processes that we named "objective-oriented structure".

Key words : Domain Model, SCORM, CMI5, Experience API, Adaptive Hypermedia, Dexter Model.

\section{INTRODUCTION}

Often, when we talk about distance learning we think immediately about E-learning or online learning. But in reality, distance learning started well before and it has an old story of almost three centuries. This story is summarized in three eras [1]:

1. First era: correspondence learning

2. Second era: learning using radio and television

3. Third era: learning using the Internet and new multimedia technologies.

The third and last era, also known as e-learning, has been defined by the European Commission as "the use of new multimedia technologies and the internet to improve the quality of learning by facilitating access to resources and services as well as remote exchanges and collaboration" [2]. Given its popularity, a lots of companies, faculties, universities and other institutions developed systems for common or personal use. Among these systems we quote 'Adobe Learning Management System' and 'Moodle' [3], which have dominated distance learning over the past two decades.

However, nowadays these systems are considered to be traditional because on the one hand, they do not respect the technological progress of the Internet and on the other hand, they are based on the old tradition of "one design for all" [4], which consider that the same course with the same structure and presentation is dedicated to all type of learners.

As a result, a new trend and generation of e-learning systems has emerged; called adaptive learning systems; which unlike traditional systems, gives learners an active role in building their knowledge and skills and also adapt the content of learning according to their preferences and needs.

These adaptive learning systems have a minimal architecture composed mainly of three interdependent models, which are:

1. Learner model: describes learner characteristics such as: personal information, skills, knowledge, learning styles, etc[5][6].

2. Adaptation model: describes the set of rules of construction and presentation responsible for the construction of the content to be delivered to the learner.

3. Domain model: describes how the information content of the application is structured [7].

So, as the main goal of our research is the design and development of an adaptive hypermedia [8] -which is one of the adaptive e-learning systems-, we proposed in our previous work both learner model [9] and adaptation model [10], then we oriented our research towards the domain model.

In general, the domain model describes how the elements (knowledge and concepts) of the course are structured. These elements could be videos, articles, assignments, quizzes [11] etc. And as we proposed in our previous work [10], we are convinced that the domain model should remain as abstract as 
possible, in the sense that it should just describe the course structures, knowledge and concepts, while ignoring all what is structure and layout of the content to be delivered to the learner.

This vision of abstraction is not supported by the two famous reference models for adaptive hypermedia: AHAM [12] and MUNICH [13] because in their domain model they go beyond the context of knowledge and concepts by introducing also the structure of the page to be delivered to the learner in the same model.

Also E-learning technical standards - like SCORM and CMI5 - were the focus of our research, because on the one hand we wanted to know how they structure the content to be delivered to the learner and on the other hand, to design a conformant contents to SCORM and CMI5.

Since these technical standards; which are considered as a reference model for Web-based e-learning content design; do not provide any conceptual model that describes them, many studies has used UML in modelling SCORM-conformant and content aggregation model [14][15]. So following this trend, we have studied their specifications and then designed their UML class Diagram.

Our designed UML class diagram of SCORM and CMI5 allowed us to notice that they are based on an architecture that we named 'content oriented', which makes the process of adaptation very complicated or even impossible to be done (not supported).

So in the following sections, we will first review all the reference models and technical standard mentioned above while detailing their architecture and justifying our remarks, then we will introduce our proposal of the domain model that implement our vision of abstraction and also based on a new architecture that we named 'objective oriented'. and finally we will present the conception of this model using the UML 2 Class Diagram while talking briefly about our next work.

\section{STATE OF ART}

Following the tradition of proposing new models, we will discuss in this section our studies on both reference models for adaptive hypermedia and E-learning technical standards.

\subsection{Reference Models}

\subsubsection{Overview}

The reference models for hypermedia began to appear before the web and gained wide acceptance as a basis for the design of hypermedia systems and interoperability tools.

The most known reference model is Dexter which provide a principled basis for comparing systems as well as for developing interchange and interoperability standards [16]. It is formally specified in $\mathrm{Z}$ language; a specification language based on set theory; and was often used as a discussion basis and extensions [17].

\subsubsection{MUNICH and AHAM}

MUNICH and AHAM are among the reference models that extend the Dexter model. They are very similar; the only major difference is that MUNICH is designed using an object oriented architecture while AHAM is expressed using a relational approach -database-.

These reference models (MUNICH and AHAM) share the same three-layer architecture composed of : the Run-Time Layer, the Storage Layer and the Within-Component Layer.

- The Run-Time layer is responsible for collecting and managing user interactions, as well as the representation of nodes and links.

- The storage layer is composed of three parts that specify what will be adapted (domain model), according to which characteristics (learning model) it will be adapted, and how it must be adapted (adaptation model).

- The within-Component Layer depends on the application.

The domain model proposed by these two reference models (which is the main topic of this paper) describes the structure of hypermedia as a collection of connected components, which form a tree or a network expressed by the composite pattern [18]. Typically, a component is an abstract representation of concepts (knowledge, information, exercise, etc.), concepts relationships, pages and fragments.

The concept relationship can refer to a link, a prerequisite or an is-part-of relation.

Also a component can have information that describing it, expressed by : attributes, presentation specification and a sequence of anchors ( Figure 1)

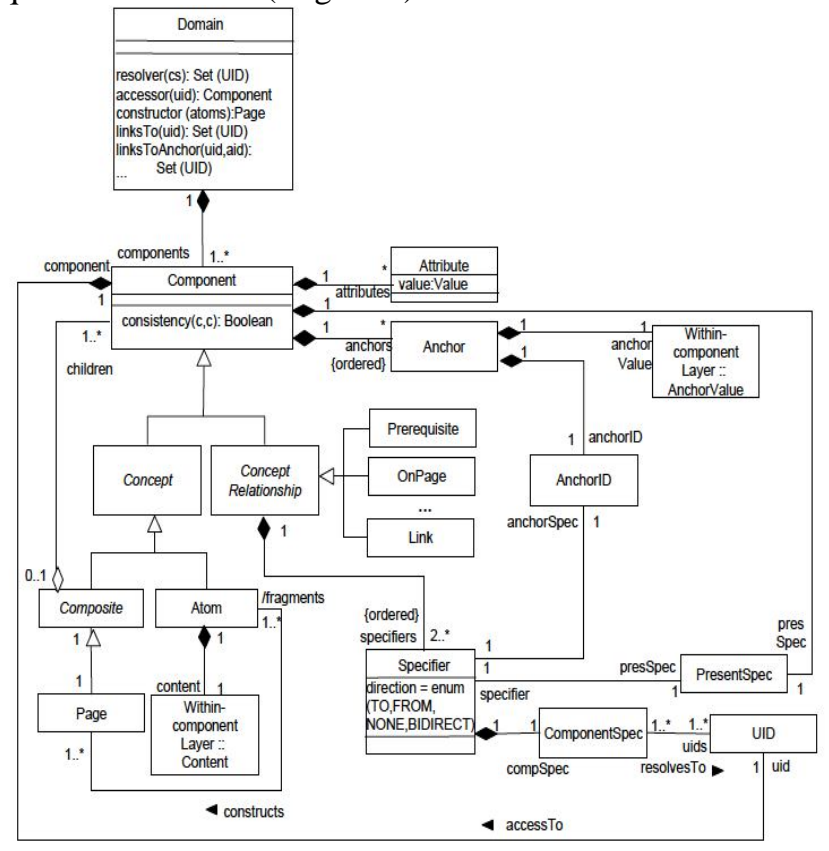

Figure 1: UML class diagram of the Domain Meta-Model of the Munich Reference Model [13]

\subsubsection{Remarks and Discussions}

MUNICH and AHAM did not propose a domain model but a domain meta-model, which is at a very high level of abstraction that only describe the model just broadly without providing details and ways of implementation. 
Despite the high level of abstraction of these domain models, we have deduced the following remarks:

The structure of the page "Page Class" is included in the model and built of several fragments; these fragments are atomic concepts that represent the content to learned. So, according to this structure, the scope of the adaptation model will be considerably reduced because the distribution of the concepts is already done in the domain model.

Also, even if the intention of the designers was just to give a formal description of how concepts are distributed in a page and let the adaptation model build its own structure of concepts to generate a page, we think that the term of page is not appropriate. From our point of view, the page should refer to or be replaced by a course or chapter of a course so that the domain model remains homogeneous by just reflecting how the concepts are structured and organized.

In addition, learning devices are very numerous and constantly evolving to the point where we can not be sure of how the content can be delivered or shown to learners in the years to come. So, we think that the inclusion of the page "Page Class" as part of the domain model is not convenient. Finally, the learned concept should have semantics. By semantics we refer to the objective or the goal behind learning a concept. ALEM [19] is one of the reference models that extend MUNICH and add concept's semantics in their work. However, it is still on a 'content-oriented' architecture where the component is the most relevant element and semantics are just added as part of the information that describes the content. Also, the use of such 'content oriented' architecture may lead to an imprecise representation of the domain knowledge structure related to learning objects [20].

\subsection{E-Learning Technical Standards}

\subsubsection{SCORM}

The Shareable Content Object Reference Model -SCORM- is a set of technical standards for e-learning software products developed by ADL [21] that is so often considered as a standard itself, but this is not the case [22].

SCORM is a reference model that defines a specific way of constructing a course content so it can be shared with other SCORM compliant systems. SCORM enables you to package your content and share it with other systems.

There are many different versions of SCORM; we chose to study SCORM 2004 because it is the latest version and also it brought two new concepts concerning navigation and sequencing.

SCORM is composed of three sub-specifications [23], which are:

1. 'The Content Packaging section' specifies how content should be described and packaged. It is based primarily on XML.

2. 'The Run-Time section' specifies how content should be launched and how it communicates with the LMS. It is based primarily on ECMAScript (JavaScript). This section will not be discussed in this paper because it had no influence on designing the domain model

3. 'The Sequencing section' describes the rules of navigation between the content (part) of the course. Expressed with XML.

Also the official SCORM specification is divided into three books. Which are:

- CAM: Content Aggregation Model [24].

- RTE: Run-Time Environment [25].

- SN: Sequencing and Navigation [26].

Only the Content Aggregation Model book was the focus of our research because it contains all the information about the course's organizational structure, the components used in the learning and the sequencing information for those components.

The SCORM organizational structure is expressed in the course's manifest file and composed of several components represented in Figure 2 from the smallest (assets) to the largest (Organisation).

In the following, we will describe each component except curriculum because it's outside of SCORM scope:

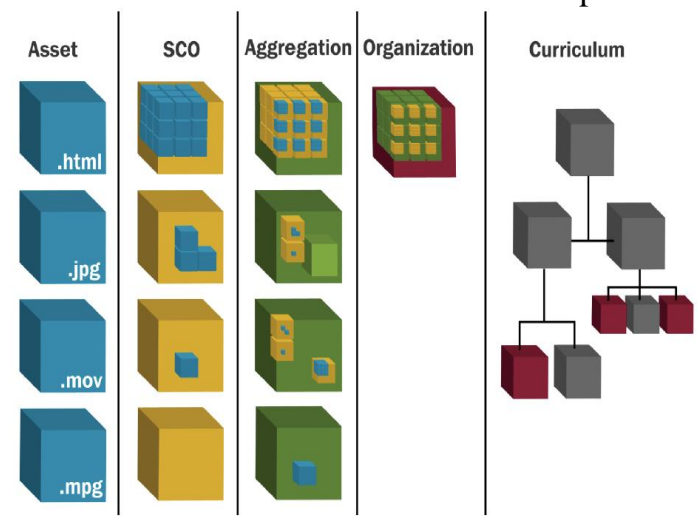

Figure 2: Components of SCORM Content [27]

Resources are a list of "parts" that make up the course. There are two types of resources, SCOs and Assets.

Assets are the physical and electronic representation of media, text, video, etc. usually, assets don't communicate with external systems which make them the most reusable items: they can be shared, redeployed, rearranged, repurposed, or reused in many different contexts and applications.

SCOs stand for Shareable Content Objects [28] and they represent the smallest logical unite that can be delivered to the learner (lesson, simulations, etc.). Generally, a SCO is composed of several assets.

Organizations are the logical groupings of course resources. A single course's manifest file can contain several organizations, but often just one organization is used called 'default organisation'.

These various organisations for a course can be used as different versions of displaying and constructing a course.

An organization has a hierarchical structure in the form of a tree. Each node (item) of this tree can have children connected to it. If the node has children it will be considered 
as aggregation, otherwise it must imperatively reference a resource (content).

Also, aggregations are not allowed to reference resources, they are collections of related SCOs and assets.

In addition to this organizational structure, SCORM support many sequencing specifications that allows content authors to:

- Control the order in which SCOs are delivered to learners.

- Specify some prerequisites to SCOs to ensure that learners know certain information or should complete a particular SCO before moving to another subject or SCO.

- Bring the learner to the last unmastered subject (remediation).

These sequencing specifications are expressed via XML and are written in the course manifest file where each activity (node / course element: Aggregations and SCO) is associated with a complete set of sequencing rules. We note that there is a default value for each sequencing rule that makes overwriting these values infrequent.

All the above was just a brief description, the full and detailed description of the course manifest structure and the sequencing definition XML binding can be found on the 'Content Aggregation Model book' [24].

So, due to this complexity, we have studied this book and several SCORM specifications [29] \& [30] to build the two Figures 3 and 4 (schema of SCORM manifest structure and sequencing definition XML Binding) that we used to design the UML2 class diagram presented later in this paper (Figure 5)..

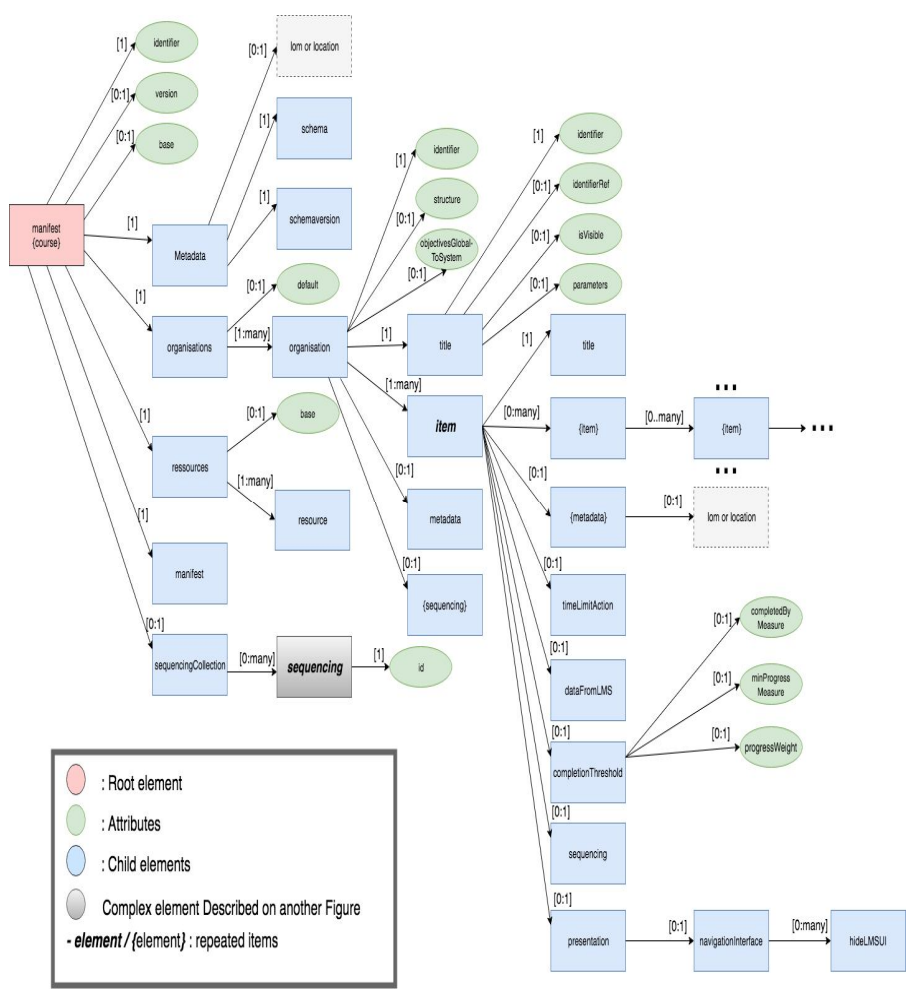

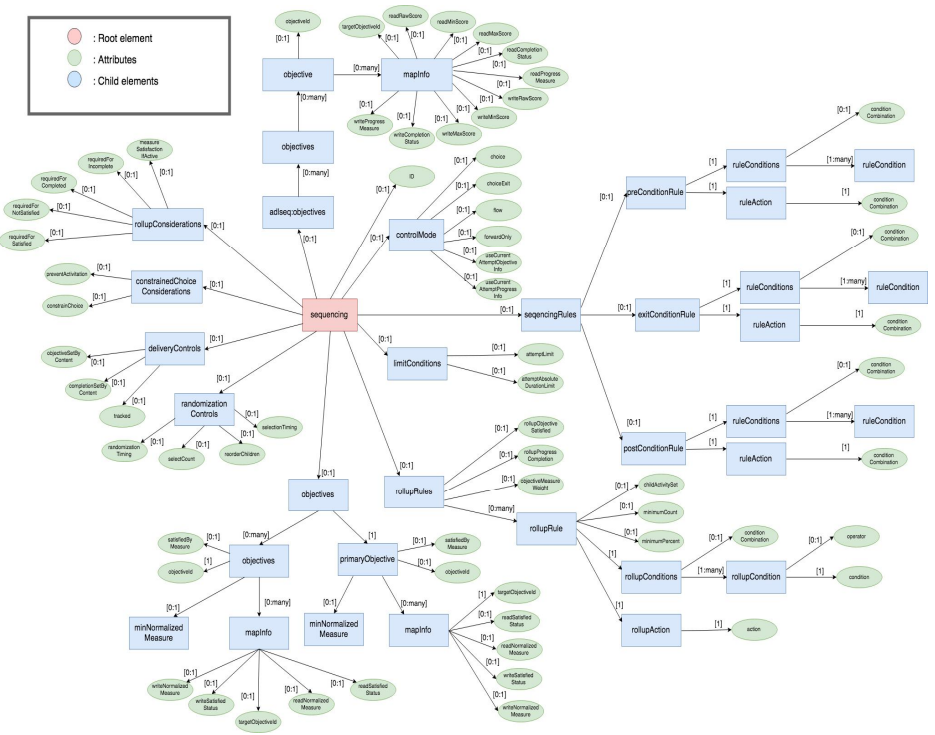

Figure 4: Schema of SCORM 2004 sequencing definition XML Binding

Our designed UML2 Class Diagram -Figure 5- looks complicated and this is normal considering the complexity of SCORM in terms of organizational structure and especially in terms of sequencing.

We used two different colours on our proposal UML2 Class Diagram of SCORM-Conformant contents -Figure 5- to make it clear that sequencing is the most dominant and complex element of SCORM to be understood and applied by the course designers.

The complexity of SCORM sequencing has been experimented by us too. First in the study phase and then in the designing phase. So we really believe that SCORM sequencing is an obstacle and barrier for the course designer when trying to apply a sequencing strategy to a course [31].

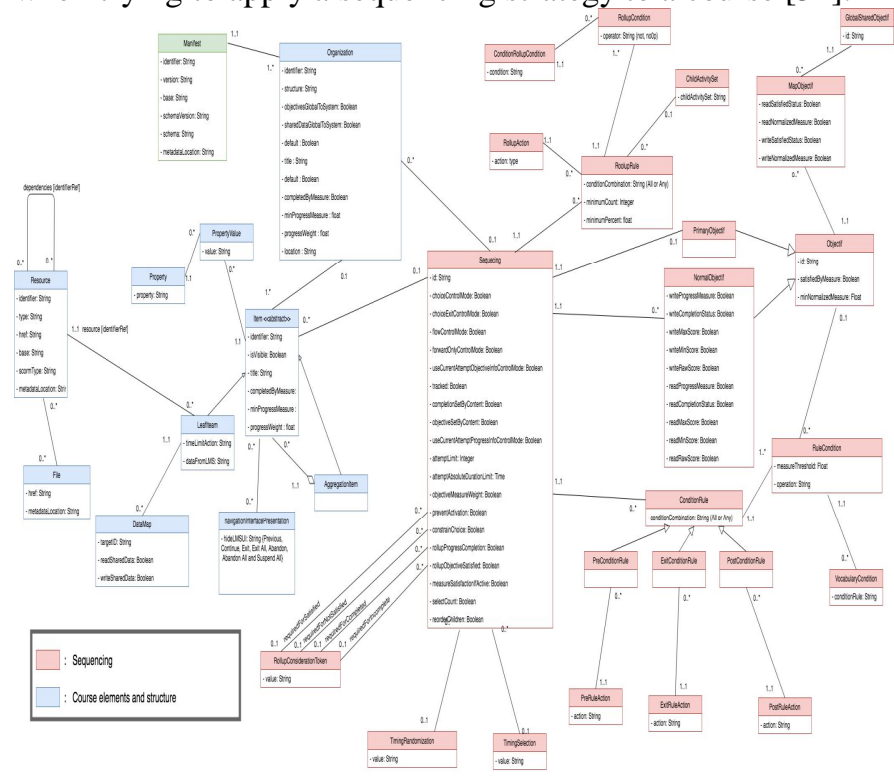

Figure 5: Our UML2 Class Diagram of SCORM-Conformant Contents

Figure 3: Schema of SCORM 2004 manifest structure 


\subsubsection{CMI5}

Before moving on to CMI5, we first need to talk about Experience API, which is a new specification of e-learning software that can record and track all types of learner experiences. These experiences are expressed using statements that are send to a Learning Record Store -LRS[32] in the form of:

I did this $\rightarrow$ I: actor, did: verb, this: object.

This new specification of learning technology is considered the most flexible and it intended to succeed SCORM that no longer follows the evolution of learning [33].

In fact, Experience API allows course designers to deploy several new features not supported by SCORM, such as [34]:

- Allows tracking of learning activities beyond the LMS (learn everywhere).

- No need to rely on browser and browser based technologies like HTML/

JavaScript.

- It supports disconnected learning scenarios.

Yet, SCORM is still useful and does things that Experience API can't do. Actually they are really unrelated to each other. This join what Art Werkenthin -President Risc, Incexpressed on a interview [35]: "both SCORM and Experience API can co-exist together but they are really unrelated to each other, in the sense that course designers can go one way or another with their modules".

Also many developers found Experience API so wide open and offers a lot of freedom. Ben Clark- SCORM developer and work for Rustici Software - explains on a interview [36] that with Experience API there is so much that developers can do to the point that they don't know what to expect out of it and how to track certain things constantly.

So CMI5 is there to put some rules back on top of Experience API, it can be considered as a use case for Experience API in the LMS World.

This new specification -CMI5- was co-developed by both ADL and the Aviation Industry Computer-Based Training Committee -AICC-. In short, CMI5 intended to take advantage of both Experience API and SCORM at the same time while addressing the limitations of each and adding new capabilities.

The 'Quartz - 1st Edition' [37] is The latest CMI5 specification that was released on 2016, this edition describe and add some rules to how use the Experience API specification with traditional learning management (LMS) systems and also describes the course structure data requirements for LMS systems.

In this paper, we will discuss only the course structure that is defined in an XML format that we studied then designed its UML2 Class Diagram (Figure 6).

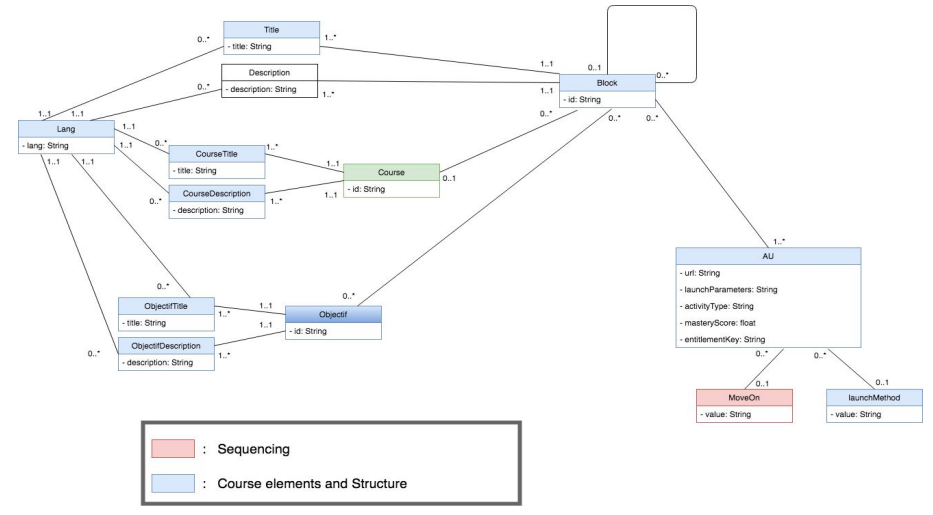

Figure 6: UML2 Class Diagram of CMI5 Course Structure Data Requirements

A course has a globally unique IRI Identifier, a title (in many languages), a description (in many languages) and several blocks.

A block has a globally unique IRI Identifier, a title (in many languages), a description (in many languages) and consists of one or more Assignable Units (AUs). Blocks can also contain references to objectives and other Blocks.

Objective has a unique IRI for the learning objective, a title (in many languages) and a description (in many languages). Finally, Assignable Unit (AU) is the main element that represents the content (resource or item in SCORM). It has A globally unique IRI identifier, launchMethod property, masteryScore property, moveOn property, activityType property, objectives, URL;A relative or fully qualified URL that references the launch point of the AU; launchParameters, entitlementKey, a title and a description (in many languages). It is clear that CMI5 course structure is way less complicated than SCORM. The following in Table 1 is a side-by-side comparison of SCORM to CMI5:

Table 1: Side-by-side comparison of SCORM to cmi5 [38]

\begin{tabular}{|l|l|l|l|}
\hline \multicolumn{1}{|c|}{ Feature } & SCORM & CMI5 & \multicolumn{1}{c|}{ Description } \\
\hline $\begin{array}{l}\text { Host content } \\
\text { anywere }\end{array}$ & No & Yes & $\begin{array}{l}\text { In SCORM all the content } \\
\text { (resources) must reside in } \\
\text { the LMS. CMI5 has no } \\
\text { restriction, the content can } \\
\text { reside anywhere, we just } \\
\text { need to specify the URL of } \\
\text { it }\end{array}$ \\
\hline Remediation & Yes & No & $\begin{array}{l}\text { SCORM remediation can } \\
\text { be implemented by } \\
\text { "simple sequencing" logic } \\
\text { rules. } \\
\text { CMI5 has no remediation } \\
\text { rules. Remediation is } \\
\text { content and LMS vendor } \\
\text { specific. }\end{array}$ \\
\hline Prerequisites & Yes & No & $\begin{array}{l}\text { SCORM prerequisites can } \\
\text { be implemented by } \\
\text { "simple sequencing" logic } \\
\text { rules. } \\
\text { CMI5 has the notion of } \\
\text { "MoveOn" criteria for the } \\
\text { completion of individual }\end{array}$ \\
\hline
\end{tabular}




\begin{tabular}{|l|l|l|l|}
\hline $\begin{array}{l}\text { Distributed } \\
\text { Content }\end{array}$ & No & Yes & $\begin{array}{l}\text { AU's. } \\
\text { In SCORM, all the content } \\
\text { is required to be located in } \\
\text { the package and typically } \\
\text { stored on the same domain } \\
\text { as the LMS. } \\
\text { CMI5 content does not } \\
\text { have to be in the package } \\
\text { and can be located on any } \\
\text { domain/local device. }\end{array}$ \\
\hline
\end{tabular}

\subsubsection{Remarks and Discussions}

Our remarks regarding SCORM and CMI5 can be divided into three main elements:

- As mentioned previously, SCORM has a very complex sequencing mechanism that really offers many features and possibilities 'Sequencing Class -Figure5-', while CMI5 was intentionally designed to not include sequencing rules in the course structure. The reason being that the customers of course structures would rather choose their own sequencing rules based on their business needs. However, this does not mean that CMI5 has no sequencing mechanism. CMI5 has the notion of "MoveOn" criteria associated to each assignable unit as a property 'MoveOn Class -Figure 6-'. This "MoveOn" property determines if the AU has been sufficiently completed by the learner in order to "move on" to the next assignable unit.

- Both SCORM and CMI5 include semantics to their content in the form of objectives. The only difference is that in SCORM, objectives can be used for sequencing logic. While in CMI5 they have no effect at all. Also, the content-oriented architecture cited above is expressed by SCORM with the 'Item Class' and in CMI5 with the 'AU Class'

- The content has only one representation (Image, video, Text ...) expressed in SCORM by the fact that an Item can have only one "href" property of the Resource Class, and in CMI5 by the fact that an Assignable Unit can have only one "URL" property.

- Finally, These E-learning technical standards (SCORM and CMI5) were intentionally designed to deliver content to a learner and are not made to support, however we have found that there is partial and minimal implementation of the adaptation of the content expressed using multiple values (in different languages) for the titles and descriptions of the element of the course. These different values can be used to adapt the content according to learner language preferences.

\section{OUR PROPOSITION}

Before introducing our proposed domain model, we will first present our design ideas and solutions for the various remarks discussed above regarding the References Models and E-learning technical standard, then we will introduce our domain model.

\subsection{Design Ideas and Solutions}

First we will continue supporting our vision of abstraction of the domain model, in the sense that we will not introduce in our proposal element that can describe a page.
Second, we have invented a new objective-oriented vision that consists of building the course around the objectives instead of the content. This new architecture gives more attention to semantics and the goals behind learning a concept. This new architecture will also facilitate the adaptation process because the hierarchical structure of the course is no longer in the form of content tree but in the form of objective tree where each objective has several types of representation. So, instead of having multiple content-oriented structures for the same course -Figure 7- where each structure refers to a type of representation, we'll just have one objective-oriented structure (Figure 8).

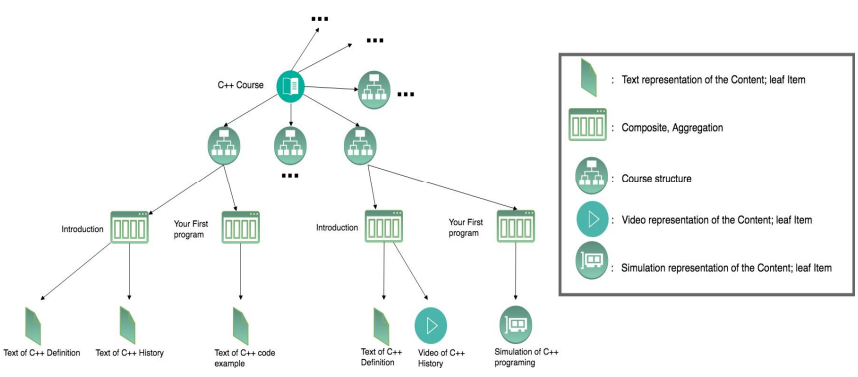

Figure 7: Example of content-oriented Course Structure

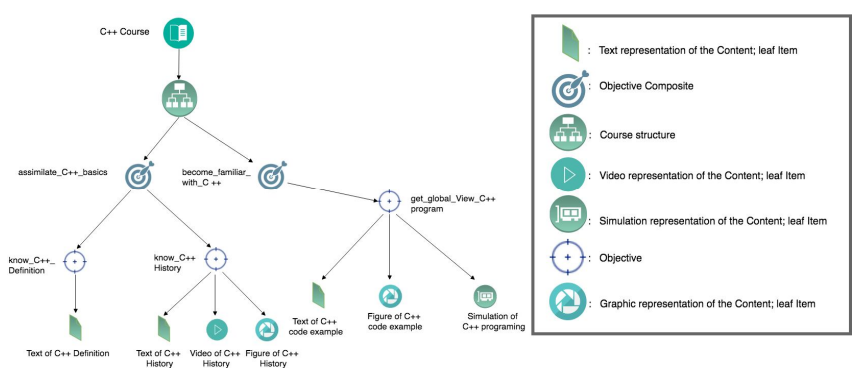

Figure 8: Example of objective-oriented Course Structure

Finally, regarding the sequencing, we used two rules:

- The first rule concerns Assignable Unit -learning content presentation-. We get inspired by CMI5 by using the notion of "MoveOn" criteria for the completion of individual AU's, which can have one of the following values [37]:

\{ "Passed","Completed","CompletedAndPassed","Compl etedOrPassed","NotApplicable"\}.

- The second rule concerns objectives. Each objective will have prerequisites that can be used either to control learning or just for information purpose.

\subsection{Our Proposition}

In Addition to the three design ideas detailed above, we introduced in our proposed domain model -Figure 9- a global structure that describes the external structure of a course. Ordered as follow:

- Discipline $>$ Course $>$ Module $>$ Lesson $>$ Chapter.

The Chapter represents the smallest logical grouping of concepts -knowledge- to be delivered to the learner, and it is composed of several objectives that have three types of relations:

1- the composite pattern: to form a logical structure of objectives in the form of a tree. 
2- Prerequisites: to express rules that can be used either to control learning -Sequencing- or just for information purpose.

3- Secondary Objectives: in Addition to the primary/principal objective, each Objective can be related to many secondary objectives. This type of relation will always be used for information purpose and have no influence in the sequencing process.

The Objective Class is the main element of our proposed Model based on the objective oriented structure. The composite objectives (CompositeObjective Class) are considered as containers for atom and composite objectives. Only atom objectives -leaf- are allowed to have an ordered list of Learning Unit (AssignedLearningUnit Class).

The learning unit -LU- represents the abstract definition of the asset or the resource used to accomplish certain objectives. Since the LU can reside everywhere -outside the system-, we used like CMI5 a relative or fully qualified URL that references the launch point of the LU.

Also, the same LU can be used by several objectives and can have many representations in different activity types (Text, image, video) and languages.

These activity types are identified by URLs; this choice follows our plan that is to include from now on the vocabulary of the Experience API and the semantic web (Table 2).

Table 2: Some Activity Types used in Experience API Vocabulary [39]

\begin{tabular}{|l|l|l|}
\hline \multicolumn{1}{|c|}{ ActivityType (URL) } & Title & \multicolumn{1}{c|}{ Description } \\
\hline $\begin{array}{l}\text { http://activitystrea.ms } \\
\text { /schema/1.0/image }\end{array}$ & image & $\begin{array}{l}\text { Represents a graphical image. } \\
\text { Objects of this type MAY contain } \\
\text { an additional fullImage property } \\
\text { whose value is an Activity } \\
\text { Streams Media Link to a full-sized } \\
\text { representation of the image }\end{array}$ \\
\hline $\begin{array}{l}\text { http://adlnet.gov/expa } \\
\text { pi/activities/media }\end{array}$ & media & $\begin{array}{l}\text { Media refers to text, audio, or } \\
\text { video used to convey information. } \\
\text { Media can be consumed (tracked: } \\
\text { completed), but doesn't have an } \\
\text { interactive component that may } \\
\text { result in a score, success, or } \\
\text { failure. }\end{array}$ \\
\hline $\begin{array}{l}\text { http://adlnet.gov/expa } \\
\text { pi/activities/simulatio } \\
\mathrm{n}\end{array}$ & simula \\
tion & $\begin{array}{l}\text { A simulation is an attempted task } \\
\text { or series of tasks in an artificial } \\
\text { context that mimics reality. Tasks } \\
\text { would likely take on the form of } \\
\text { interactions, or the simulation } \\
\text { could be self-contained content. }\end{array}$ \\
\hline
\end{tabular}

Finally, the Launch Parameters class and the attribute 'masteryScore' were intentionally included twice, first in the learning unit and then in the atom objective, for the simple reason of giving course designers the choice to provide their own values while recommending the use of the default ones, and this is clear in our UML class diagram proposed in Figure 9.

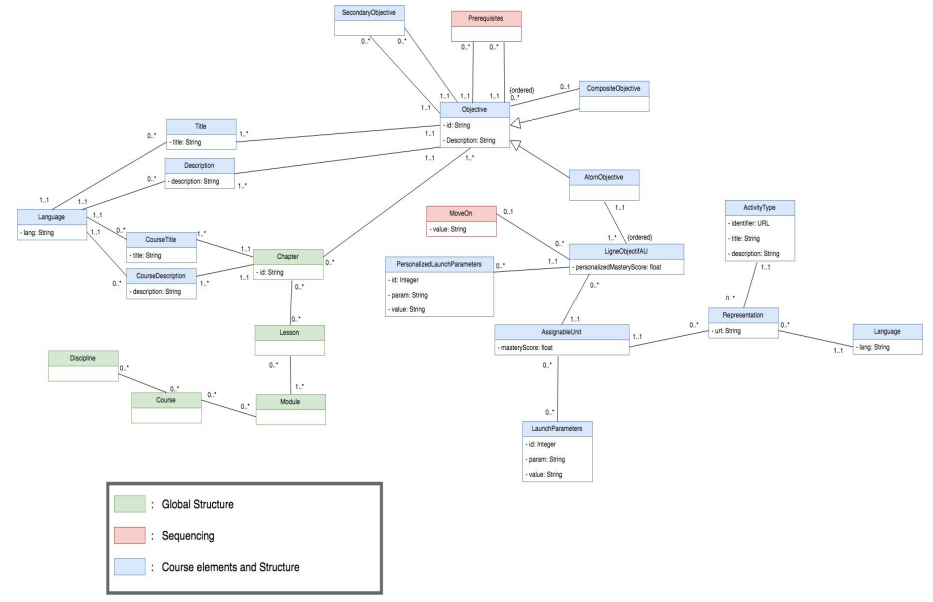

Figure 9: UML2 Class Diagram of the Domain Model Proposed

\section{CONCLUSION AND PERSPECTIVES}

The domain model that we designed represents the last fragment of the puzzle to develop our adaptive hypermedia. We are aware that an implementation and tests are required to validate our model. In particular, the objective oriented structure that we invented and introduced for the first time. For this purpose, the main theme of our next work will have a technical and experimental character by first, linking the three models (learner model, adaptation model and domain model) and making the necessary modifications to support the Experience API to its fullest. Then, develop and test our adaptive hypermedia system that is our final goal.

\section{REFERENCES}

1. Bertolini,M. (2014). Petite histoire de la formation à distance - infographie. Available: https://format30.com/2014/02/04/petite-histoire-de-la-f ormation-a-distance-infographie/.

2. European Commission. (2005). Bringing knowledge within reach. IS Policy, Fact sheet 5

3. Srimathi,H. Srivatsa, S. K. (2009). SCORM-compliant personalized elearning using instructional design principle. International Conference on Signal Processing Systems, ICSPS 2009, pp. 738-742.

4. Kaya, G. Altun, A. (2011). A Learner Model for Learning Object Based Personalized Learning Environments. Commun. Comput. Inf. Sci., vol. 240. https://doi.org/10.1007/978-3-642-24731-6_35

5. Sami Hachmoud, Adil Hachmoud, Anwar Meddaoui, Hakim Allali (2019). Analysis of Students Online Learning Behavior in a Pedagogical Model combining Blended Learning andCompetency Based Approach. International Journal of Advanced Trends in Computer Science and Engineering, Volume 8, No.6. https://doi.org/10.30534/ijatcse/2019/113862019

6. Drissi, S., Bensebaa, T., Lafifi, Y. (2009). Une nouvelle approche pour l'adaptation d'un hypermédia pédagogique au profil cognitif de l' apprenant en utilisant XML. 2nd Conférence Internationale sur l'Informatique et ses Applications (CIIA'09). 
7. Wu, P. M. E., Houben, G.J., De Bra, P.M. (2000) . Supporting user adaptation in adaptive hypermedia applications. Proceedings Conferentie Informatiewetenschap 2000, vol. Vol. 00-20, pp. 88-98.

8. Mehdi TMIMI, Mohamed Benslimane, Abdelali Ibriz, Kamar Ouazzani (2019). Proposal of a complete model and architecture of an intelligent adaptive hypermedia. International Journal of Advanced Trends in Computer Science and Engineering, Volume 8, No.4. https://doi.org/10.30534/ijatcse/2019/70842019

9. Tmimi, M.,Benslimane, M. Berrada, M., Ouazzani K. (2017). A Proposed Conception of the Learner Model for Adaptive Hypermedia. International Journal of Applied Engineering Research, vol. 12, no. 24.

10. Tmimi M., Benslimane M., Berrada M., Ouazzani K., (2019). Implemented and Tested Design Proposal of Adjustment Model for Adaptive Hypermedia. International Journal of Emerging Technologies in Learning (iJET). Vol 14, No 02

https://doi.org/10.3991/ijet.v14i02.8230

11. Madaio M., (2015). Adaptive Learning Systems The State of the Field. C21U Seminar, UnConference Room.

12. De Bra, P.M., Wu P. M. E., Houben, G.J., (1999). AHAM : A Dexter-based Reference Model for Adaptive Hypermedia. Proceedings of the 10th ACM Conference on Hypertext and Hypermedia: Returning to Our Diverse Roots, pp. 147-156. https://doi.org/10.1145/294469.294508

13. Koch, N., Wirsing M., (2002). The Munich Reference Model for Adaptive Hypermedia Applications An Overview of the Reference Model. 2nd International Conference on Adaptive Hypermedia and Adaptive Web-based Systems, pp. 213-222.

14. Kim, J. S., Park Y. G., (2009). Mapping method of SCORM content aggregation model for e-learning content design. Fifth International Joint Conference on INC, IMS and IDC, pp. 2010-2015.

15. Hu, S. C., (2005). Application of the UML in modeling SCORM-conformant Contents. Fifth IEEE International Conference on Advanced Learning Technologies (ICALT'05), pp. 200-201.

16. Halasz, F., Schwartz, M., (1994). The Dexter hypertext reference model. Communication of ACM, vol. 37, no 2.

https://doi.org/10.1145/175235.175237

17. Koch, N., (2003). An Object-Oriented Hypermedia Reference Model Formally Specified in UML. In Information Modeling for Internet Applications, van Bommel P. (Ed.), IGI Publ., pp. 59-78.

18. Sellarès,T., (2006). Composite Pattern. University of Girona, Software Engineering. Available: http://ima.udg.edu/ sellares/EINF-ES1/CompositeToni. pdf . Accessed 19 june 2019.

19. Tadlaoui, M., Chikh, A., Bouamrane,K., (2010). ALEM : Un Modèle de Référence pour les Applications Web Adaptatif Educatif. Actes de la lère
Conférence internationale LEAFA $2010 \ll e$-Learning For All».

20. Zhu X. H., Zhang B., and Zhang Y., (2009). A learning object organization model based on conceptual domain. International Conference on Computational Intelligence and Software Engineering, pp. 1-4. https://doi.org/10.1109/CISE.2009.5364865

21. Advanced Distributed Learning - ADL Initiative. 2010.Available:https://www.immagic.com/eLibrary/AR CHIVES/GENERAL/US_DOD/A100221I.pdf

22. Maratea, A., Petrosino A., Manzo, M., (2012). Integrating navigational and structural information in SCORM content aggregation modeling. IEEE 12th International Conference on Advanced Learning Technologies- Rome, pp. 379-380. https://doi.org/10.1109/ICALT.2012.161

23. Rustici Software, What is SCORM?. SCROM Explained.Available:http://www.scorm.com/scorm-expl ained/.

24. Advanced Distributed Learning -ADL-, (2009). Content Aggregation Model (CAM). SCORM 2004 4th.

25. Advanced Distributed Learning -ADL-, (2009). SCORM 2004 Run-Time Environment [RTE]. SCORM 2004 th Ed. v1.1.

26. Advanced Distributed Learning -ADL-, (2009). Sequencing and Navigation (SN). SCORM 2004 4th Ed.

27. Advanced Distributed Learning -ADL-, (2011). SCORM Users Guide for Programmers. - Version 10 -..

28. Advanced Distributed Learning -ADL-, (2011). SCORM Users Guide for Instructional Designers.

29. Rustici M., (2009). SCORM - SCORM 2004 Manifest Structure - SCORM -. Available: https://scorm.com/scorm-explained/technical-scorm/co ntent-packaging/manifest-structure .

30. Rustici M., (2009). SCORM 2004 Sequencing Definition XML Binding. Available: https://scorm.com/scorm-explained/technical-scorm/co ntent-packaging/sequencing-definition-structure .

31. Melia, M., Barrett, R.,Pahl, C., (2006). A Model-based Approach to SCORM Sequencing. the Sixth Annual Irish Educational Technology User's Conference (EdTech06) - Research Track. ILTA.

32. Lim, K. C., (2015). Case Studies of xAPI Applications to E-Learning. The Twelfth International Conference on eLearning for Knowledge-Based Society. p. 3.1-3.12.

33. Gschwind, J. (2016). White Paper - 2016 Trends: The Experience API \& Learning Analytics, Expertus.

34. Chew,L. K., (2015). Tracking Learning Experiences Using the Experience API. eLearning Forum Asia 2015.

35. Werkenthin, A. (President Risc. Inc). (2015). What is cmi5? Art Werkenthin explains. Available : https://www.youtube.com/watch? $v=j 0$ Lci2tesU8\&list $=P$ Llv_yyODMQs5t2aom5cYp1Z5Dv6BxMVkg\&index $=3$.

36. Clark, B., (2015) What is cmi5? Ben Clark explains.Available:https://www.youtube.com/watch? $v=$ 
ZNETexCpHsk\&list=PLlv_yyODMQs5t2aom5cYp1Z5D v6BxMVkg.

37. Cohen E. et al., (2016) AICC / CMI5_Spec_Current cmi5 Specification Profile for xAPI. AICC. Available: https://github.com/AICC/CMI-5_Spec_Current/blob/qu artz/cmi5_spec.md.

38. ADL-AICC, SCORM vs cmi5 Comparison. The cmi5 Project.Available:http://aicc.github.io/CMI-5_Spec_Cu rrent/SCORM.

39. XAPI Communities of Practice \& Profiles Group and XAPI Profile Specification Group. ALL ACTIVITY TYPES.THE XAPI VOCABULARY \& PROFILE. http://xapi.vocab.pub/activity-types/index.html 